\title{
Mathematically Facile Adolescents With Math-Science Aspirations: New Perspectives on Their Educational and Vocational Development
}

\author{
Rose Mary Webb, David Lubinski, and Camilla Persson Benbow \\ Vanderbilt University
}

\begin{abstract}
This longitudinal study tracked 1,110 adolescents identified as mathematically precocious at Age 13 (top $1 \%$ ) with plans for a math-science undergraduate major. Participants' high school educational experiences, abilities, and interests predicted whether their attained undergraduate degrees were within math-science or nonmath-nonscience areas. More women than men eventually completed undergraduate degrees outside math-science, but many individuals who completed nonmath-nonscience degrees ultimately chose math-science occupations (and vice versa). At Age 33, the 2 degree groups reported commensurate and uniformly high levels of career satisfaction, success, and life satisfaction. Assessing individual differences is critical for modeling talent development and life satisfaction; it reveals that equal male-female representation across disciplines may not be as simple to accomplish as many policy discussions imply.
\end{abstract}

The male-female disparity in math and science is well documented and is particularly apparent at rising levels along the educational-vocational continuum (Lane, 1999; Lawler, 1999, 2002; Mervis, 1999a, 1999b, 2000; Sax, 2001; Seymour \& Hewitt, 1997; Wickware, 1997). In the scientific literature, sex differences in the math-science pipeline are a highly charged topic at the core of much ardent discourse, described as "squandering half of their scientific potential" ("How to boost the careers of women in science?," 1999, p. 99), as "hemorrhaging ... from the SET [science, engineering, and technology] pipeline" (Commission on the Advancement of Women and Minorities in Science, Engineering and Technology Development [CAWMSET], 2000, p. 14), and as a "leaky pipeline" of "women drop[ping] out of research" (Wickware, 1997, p. 202). This pattern of provocative dialogue implies that there is a vast repository of wasted potential that would be utilized if only enlightened policies were enacted.

Many special councils have convened to understand the causes of and construct solutions to this apparent problem (CAWMSET, 2000; Committee on Women Faculty, 1999; National Science Foundation, 1996), purporting "a key to the full integration of women in science and engineering is the increase in their numbers" (National Research Council, 2001, p. 220). Indeed, many resources have been devoted to equalizing representation between

Rose Mary Webb, David Lubinski, and Camilla Persson Benbow, Department of Psychology and Human Development, Vanderbilt University.

This article is based on a thesis submitted by Rose Mary Webb to Vanderbilt University in partial fulfillment of requirements for the master of science degree. Support for this article was provided by National Science Foundation Grant MDR8855625, an anonymous donor, and a Templeton Award for Positive Psychology. Earlier versions of this article benefited from comments by John A. Achter, April Bleske-Rechek, and Julian C. Stanley.

Correspondence concerning this article should be addressed to David Lubinski, Department of Psychology and Human Development, Vanderbilt University, Box 512 Peabody Station, Nashville, Tennessee 37203. E-mail: david.lubinski@vanderbilt.edu the sexes in various engineering and scientific endeavors. Recently, the U.S. Congress established the Commission on the Advancement of Women and Minorities in Science, Engineering and Technology (CAWMSET) to develop methods of retaining women (and other underrepresented groups) in the sciences. An explicit goal of this commission is to establish demographic parity between the science-technology workforce and the workforce of the nation at large (CAWMSET, 2000). Even at major universities, such as Massachusetts Institute of Technology (MIT), initiatives have been launched to increase the representation of women faculty (Committee on Women Faculty, 1999; Lawler, 1999, 2002).

These approaches to ensuring equal representation of men and women across disciplines seem to assume that the observed disparity is essentially the result of cultural conditioning and limited opportunities for women (e.g., "an uneven playing field"; National Council for Research on Women, 2001, p. 15). To suggest that increased representation of women in engineering could be achieved if they could only see its relevance (e.g., "designing different kinds of equipment for the kitchen"; Brainard, as quoted in Holden, 2000, p. 380) only serves to underscore the lack of empirical evidence and the speculative nature of this discourse. There is little evidence available to draw on in evaluating the advisability or potential effectiveness of strategies aimed at malefemale parity (Holden, 2000; Kleinfeld, 1998-1999).

In fact, such strategies ignore vital personal-attribute dimensions of human capital relevant to talent development (Lubinski \& Benbow, 2000). Recent longitudinal studies of mathematically precocious young adolescents have revealed some intriguing sex differences in ability and interest patterns that parallel the observed male-female disparities in math-science (Benbow, Lubinski, Shea, \& Eftekhari-Sanjani, 2000; Schmidt, Lubinski, \& Benbow, 1998; Shea, Lubinski, \& Benbow, 2001). Although the sexes are comparable in terms of overall general intellectual ability (Halpern, 1997; Jensen, 1998), women tend to excel in verbal abilities and skills, whereas men excel in mathematical and spatial reasoning abilities. This pattern also has been observed cross culturally in more normative populations of children, adolescents, and adults 
(Geary, 1996, 1998; Halpern, 2000; Hedges \& Nowell, 1995; Humphreys, Lubinski, \& Yao, 1993; Kimura, 1999). In addition, interest patterns show that, from an early age, men more exclusively focus on investigative and theoretical pursuits, whereas women are more equally divided among these areas and artistic and social domains (Achter, Lubinski, \& Benbow, 1996; Lubinski \& Humphreys, 1990; Schmidt et al., 1998). Collectively, ability and interest patterns are among the most important types of information to consider for educational-vocational counseling (Dawis, 1992; Tyler, 1974)

Given that men and women do not differ in general intelligence but do differ on these critical specific ability and interest dimensions, it is not surprising that a recent 20-year follow-up of nearly 2,000 mathematically precocious youth revealed essentially no sex differences in earned educational credentials, yet the areas in which they secured those credentials did vary systematically: Women earned more degrees in the humanities and life sciences, and men earned more degrees in math and inorganic sciences (Benbow et al., 2000). A working hypothesis emanating from this research is that the observed sex differences in educationalvocational outcomes emerge from sex differences in specific abilities and interests, which influence women and men to make different choices.

Therefore, in Phase I of this study, we asked the following questions: Of mathematically gifted students who begin undergraduate studies in math-science, what differentiates those who remain in math-science from those who opt to pursue 4-year degrees in other areas? Is it essentially a function of sex discrimination and cultural conditioning, or could it be, in part, the result of differing personal attributes of men and women leading to different educational and vocational choices (Lubinski, Benbow, Shea, Eftekhari-Sanjani, \& Halvorson, 2001)? Other research (Achter, Lubinski, Benbow, \& Eftekhari-Sanjani, 1999) has shown that global educational-vocational preference dimensions add incremental validity over abilities in the prediction of attained undergraduate major, but will interests predict the eventual majors of mathematically gifted students who all had initially declared a math-science major?

The second component of this study addressed the current lack of information regarding the outcomes of individuals who leave the math-science pipeline. Two implicit assumptions seem to operate to promote this void in the study of attrition in mathscience: first, that talent relevant to the development of scientific expertise is constrained to math-science domains, and second, that a loss to society is encountered whenever an individual with math-science talent chooses to develop along an educationalvocational track outside of math-science. We question these assumptions. First, math and science skills are critical for countless career paths and are valuable in meeting the technological demands of many disciplines in our contemporary world of work (Rivera-Batiz, 1992). Second, individuals who leave math-science domains may not simply "drop out," as much of the pejorative discourse implies; but instead, they may go on to make important contributions in their chosen fields.

Thus, in Phase II of this study, we asked the following questions: What are the eventual outcomes of mathematically gifted individuals who chose to leave the math-science pipeline, and how do those outcomes compare with those of individuals who remained in math-science domains? How do they conceptualize their departure: as a result of options being limited to them or as a process of aligning themselves with their abilities and interests? To the extent that people find learning and work environments congruent with their personal preferences and ability strengths, a prominent theory of educational-vocational adjustment predicts that satisfaction (fulfillment) and satisfactoriness (competence), respectively, will be maximized (Dawis \& Lofquist, 1984). And, indeed, Benbow et al.'s (2000) 20-year follow-up found no significant sex differences in career (and life) satisfaction and success. However, Benbow et al. did not isolate for examination individuals who made a commitment to earn a 4-year mathscience degree as we do here, which allows us to directly compare those who secured their 4-year degrees in math-science with those who secured their 4-year degrees in nonmath-nonscience disciplines.

Although math-science male-female disparities are observed at all levels, the disparity increases exponentially at higher levels along the educational-vocational continuum (National Research Council, 2001). For example, a recent study of women in science reported a 1.5:1.0 male:female ratio of undergraduates in the School of Science at MIT but a more than 11.4:1.0 male:female ratio of faculty in science (Committee on Women Faculty, 1999). This seven-fold increase in the male:female ratio parallels the greater male, relative to female, variability observed in many ability domains (Geary, 1996), which results in greater representation of men at both extremes of the distribution. The pool of individuals at promise for filling the high-level positions where these differences are particularly striking is certainly an exceptional one. Therefore, to address disproportionate representation in such high-level positions requires a highly select sample. A sample of mathematically precocious students identified at an early age, as we have here, is ideal. By examining the experiences of students who reported intentions to pursue math-science degrees at Age 18 and with more than enough ability for securing math-science degrees, we hoped to, for the first time, gain some insight regarding those who have opted to develop in domains outside math-science.

In summary, we examined two general topics. In Phase I, we investigated the determinants of attrition in math-science among mathematically talented individuals who reported plans to major in math-science at the onset of their undergraduate studies, contrasting math-science degree recipients to nonmath-nonscience degree recipients. In Phase II, we compared the subsequent educationalvocational development and long-term outcomes of both degree groups.

\section{Method}

\section{Participants}

Participants were selected from the Study of Mathematically Precocious Youth (SMPY), a longitudinal project designed to study the development of intellectual talent throughout the lifespan (Lubinski \& Benbow, 1994). SMPY participants were initially identified through annual talent searches, a method that begins by selecting students in the seventh or eighth grade who score at or above the 97 th percentile of all students taking routinely administered standardized achievement tests in their schools. Because the performance of this group is at the ceiling of the conventional tests given to their age group, above-level testing was then utilized to further differentiate among individuals in this select group. This was accomplished 
through the administration of college entrance exams, such as the SAT. Talent-search 12- to 13-year-olds consistently generate SAT score distributions similar to those of high school students.

SMPY participants were identified between 1972 and 1979 and were drawn from the mid-Atlantic states. These individuals were identified as being within at least the top $1 \%$ of ability for their age group on the basis of their SAT scores. Before Age 13, these participants scored at least 390 on the mathematics portion of the SAT (SAT-M) or at least 370 on the verbal portion of the SAT (SAT-V); 2,781 individuals (1,774 men, 1,007 women) were included (Lubinski \& Benbow, 1994). The present study included 1,110 (760 male, 350 female) SMPY participants who indicated that they anticipated an undergraduate major in math-science and for whom received degree majors were known.

\section{Instruments}

SAT. The SAT comprises two subtests: a mathematical reasoning portion (SAT-M) and a verbal portion (SAT-V). Participants reported high school SAT scores at the first follow-up survey after high school. Complete SAT scores are available for $95.1 \%$ of study participants.

Measures of interest. The Study of Values (SOV) assesses the relative prominence of six personality-related values: theoretical, economic, aesthetic, social, political, and religious (Allport, Vernon, \& Lindzey, 1970). Because the SOV is an ipsatively scaled measure, the sixth dimension is completely redundant with respect to the intraindividual profile, so only five dimensions will be reported here (political was deleted). Study participants took the SOV at Age $13(n=262,23.6 \%$ of total sample $)$ and in some later follow-ups. Holland's Occupational Codes (HOC) are based on Holland's RIASEC (viz., realistic, investigative, artistic, social, enterprising, and conventional) conceptualization of interest dimensions; participants completed the HOC at Age $13(n=273,24.6 \%)$. Although the HOC is not used as an analysis variable, it provides a method of estimating missing values on the SOV, as do the post-Age 13 SOV assessments. Age 13 assessments on the HOC, RIASEC, and SOV for this special population have demonstrated construct validity (Achter et al., 1999; Schmidt et al., 1998), longitudinal stability (Lubinski, Benbow, \& Ryan, 1995; Lubinski, Schmidt, \& Benbow, 1996), and incremental validity over SAT scores (Achter et al., 1999) for educational criteria.

High school coursework. The first high school coursework measure represents the number of advanced mathematics and inorganic science courses taken (of calculus, physics, chemistry, advanced physics, and advanced chemistry). The second measure is a dichotomous variable reflecting whether an individual's favorite course in high school was within any math-science domain. Complete data for these two measures are available for $98 \%$ and $93 \%$ of study participants, respectively.

\section{Procedure}

At approximately Age 13, participants completed a background questionnaire and numerous standardized assessments. Specific assessments varied, so complete data on all participants are not available. At approximately Age 18, participants were mailed their first follow-up questionnaire, which consisted primarily of educational queries regarding participants' high school experiences and plans for college. Participants were asked to report their expected undergraduate major; this variable served as a criterion for inclusion in the present study. Table 1 provides a complete list of included math-science intended majors.

At approximately Age 23, participants were mailed the next follow-up questionnaire. In addition to queries regarding their undergraduate experiences, this survey investigated participants' achievements, attitudes and personal preferences, and their future educational and vocational plans. This follow-up provided the criterion variable used to determine group membership here, namely, whether the participant actually received an undergraduate degree in math-science as intended 5 years prior. At ap-
Table 1

Categories of Expected Undergraduate College Majors, Percentages by Sex

\begin{tabular}{lccc}
\hline \multicolumn{1}{c}{ Field } & Men & Women & ES \\
\hline Engineering & 43.4 & 22.9 & $0.43^{* *}$ \\
Mathematics & 15.9 & 21.1 & $-0.13^{*}$ \\
Biological science & 13.4 & 23.4 & $-0.26^{* *}$ \\
Computer science & 8.3 & 6.0 & 0.08 \\
Medical science & 3.6 & 12.9 & $-0.34^{* *}$ \\
Physical science & 8.8 & 1.4 & $0.41^{* *}$ \\
Chemistry & 5.0 & 8.0 & -0.12 \\
Earth science & 1.2 & 2.3 & -0.08 \\
Agricultural science & 0.4 & 2.0 & -0.10 \\
\hline
\end{tabular}

Note. All values in table represent proportions of participants, by sex, who reported plans to major in each math-science area (760 men, 350 women). Positive effect sizes (ES) reflect greater male proportion, and negative effect sizes reflect greater female proportion.

$* p<.05, * * p<.01$ (following Cohen, 1988, Table 6.3, pp. 192-195).

proximately Age 33, participants were mailed the next follow-up questionnaire. The primary focus of this stage of data collection was graduate education and vocational choice, supplemented by attitudes and personal preferences. Information regarding undergraduate degrees also was collected at this point and was used to determine group membership for participants with missing data on this variable from the Age 23 survey.

Participants were categorized into two groups on the basis of their received undergraduate major: Participants receiving a degree in any of the math-sciences, as intended, will be referred to as the math-science group (633 men, 259 women); participants receiving a degree outside the mathsciences, contrary to their initial plans, will be referred to as the nonmathnonscience group (127 men, 91 women). See Table 2 for a complete list of major areas. These groups, examined separately by sex, serve as the primary contrast throughout the study.

\section{Management of Missing Data}

Because of SMPY's longitudinal nature, variables had missing values for some observations; therefore, the missing values were estimated. Missing values for the high school math-science coursework variables (number of advanced math-science courses and favorite course) were replaced with the sum of the proportions of the complete sample indicating each class and the proportion of the complete sample indicating a math or science class as favorite, respectively. Using the entire SMPY dataset $(N=2,781)$ described previously, SAT scores were regressed, by sex, on all ability and coursework-related variables (635 male, 325 female complete cases), and SOV scores were regressed on SAT scores and all other interest variables (97 male, 42 female complete cases). The resulting regression equations were then applied to the subsample addressed in this study to yield a complete data matrix for the forthcoming analyses.

Squared multiple correlations were greater for ability and coursework measures (.47-.59) than for SOV scores (.24-.56). Although there was little difference between the imputed and observed statistics for ability and coursework measures, the variance estimates for the complete (imputed) SOV scales were much smaller than those for the matrix of observed cases. Given the conditions under which missing values on the SOV were imputed, the sensitivity of the SOV scales as potential predictors is likely to be attenuated.

\section{Results}

Results are presented in two phases. The first phase presents data regarding the high school variables relevant to the prediction 
Table 2

Categories of Received Undergraduate College Majors, Percentages by Sex

\begin{tabular}{|c|c|c|c|}
\hline Field & Men & Women & ES \\
\hline \multicolumn{4}{|c|}{ Math-science } \\
\hline Engineering & 40.9 & 17.4 & $0.54 * *$ \\
\hline Biological science & 9.5 & 18.9 & $-0.26 * *$ \\
\hline Mathematics & 9.3 & 10.9 & -0.07 \\
\hline Computer science & 8.0 & 6.6 & 0.04 \\
\hline Chemistry & 5.0 & 5.1 & -0.01 \\
\hline Physical science & 7.0 & 0.9 & $0.34 * *$ \\
\hline Medical science & 1.8 & 11.4 & $-0.39 * *$ \\
\hline Agricultural science & 0.5 & 1.7 & $0.17 *$ \\
\hline Earth science & 1.2 & 1.1 & 0.01 \\
\hline Total & 83.3 & 74.0 & $0.22 * *$ \\
\hline \multicolumn{4}{|c|}{ Nonmath-nonscience } \\
\hline Business \& economics & 8.6 & 11.7 & -0.10 \\
\hline Social science & 3.8 & 4.9 & -0.05 \\
\hline English & 1.2 & 2.3 & -0.08 \\
\hline Arts & 0.3 & 1.7 & $-0.22 * *$ \\
\hline Philosophy \& religion & 0.8 & 0.6 & 0.04 \\
\hline Languages & 0.1 & 1.7 & $-0.26 * *$ \\
\hline History & 0.4 & 0.6 & -0.04 \\
\hline Communications & 0.3 & 0.3 & 0.00 \\
\hline Education & 0.1 & 0.9 & $-0.16^{*}$ \\
\hline Environmental design & 0.1 & 0.3 & -0.04 \\
\hline General studies & 0.3 & 0.0 & 0.06 \\
\hline Other & 0.8 & 1.1 & -0.05 \\
\hline Total & 16.7 & 26.0 & $-0.22 * *$ \\
\hline
\end{tabular}

Note. All values in table represent proportions of participants, by sex, who received undergraduate degrees in each area (760 men, 350 women). Positive effect sizes (ES) reflect greater male proportion, and negative effect sizes reflect greater female proportion.

$* p<.05, * * p<.01$ (following Cohen, 1988, Table 6.3, pp. 192-195).

of degree group membership (math-science vs. nonmathnonscience) and constitutes the predictive component of this investigation. The second phase examines the nature of the educational and vocational development of participants across a 15-year interval: high school to Age 33 .

\section{Phase I}

Phase I first presents descriptive data on participants' high school educational experiences (coursework and course preferences), abilities, and interests. These variables are then utilized in a discriminant function analysis to investigate their effectiveness in predicting whether participants completed a math-science undergraduate degree.

Abilities. SAT means (and standard deviations) for each degree group are as follows: math-science men: SAT-M $=723.2$ (56.5), SAT-V = 608.8 (83.1); nonmath-nonscience men: SAT$\mathrm{M}=688.1$ (67.3), SAT-V $=575.7$ (87.8); math-science women: SAT-M $=674.1$ (62.3), SAT-V $=612.6$ (81.4); and nonmathnonscience women: SAT-M $=656.4$ (67.6), SAT-V $=603.3$ (81.7). Effect size differences (Cohen, 1988) between degree groups, within sex, are as follows. Math-science men exhibited higher mean scores than nonmath-nonscience men on both SAT subtests: SAT-M: $d(632,126)=.60, p<.01$; SAT-V: $d(632$, $126)=.39, p<.01$. Women exhibited the same pattern, but the differences were less striking: SAT-M: $d(258,90)=.28, p=.02$; SAT-V: $d(258,90)=.11, n s$. Further analysis of effect size differences between men and women, within degree group, revealed that for math-science participants, men exhibited higher mean SAT-M scores than women, $d(632,258)=.84, p<.01$, and, although women exhibited slightly higher mean SAT-V scores than men, that difference was not statistically significant, $d(632$, $258)=-.05, n s$. For nonmath-nonscience participants, men demonstrated higher mean SAT-M scores than women, $d(126,90)=$ $.47, p<.01$, and women exhibited higher mean SAT-V scores than men, $d(126,90)=-.32, p<.02$.

Interests. Among men, but not women, math-science and nonmath-nonscience groups varied somewhat in their SOV profiles. Math-science men more prominently displayed theoretical, $d(632,126)=.28, p<.01$, and economic, $d(632,126)=.43, p<$ .01 , themes, and nonmath-nonscience men more prominently evinced social, $d(632,126)=-.34, p<.01$, and religious $d(632$, $126)=-.20, p=.04$, themes. The social dimension exhibited a similar, but marginally nonsignificant, difference between the two female groups, $d(258,90)=-.22, p=.07$. No other significant differences between degree groups were found.

High school coursework. The mean number (and standard deviation) of math-science courses taken in high school by each degree group is as follows: math-science men $=3.3(0.9)$, nonmath-nonscience men $=2.7(1.2)$, math-science women $=2.8$ (0.9), and nonmath-nonscience women $=2.3$ (1.0). Significant differences between degree groups, within sex, are apparent for both men and women: math-science men took, on average, more math-science courses than nonmath-nonscience men, $d(632$, $126)=.68, p<.01$, and math-science women took, on average, more math-science courses than nonmath-nonscience women, $d(258,90)=.51, p<.01$. Moreover, significant sex differences, within degree group, are apparent: For math-science participants, men took, on average, more math-science courses than women, $d$ $(632,258)=.64, p<.01$, and for nonmath-nonscience participants, men took, on average, more math-science courses than women, $d(126,90)=.38, p<.01$.

The proportion of each group indicating that their favorite high school course was within the math-science domain was as follows: math-science men $=86 \%$, nonmath-nonscience men $=67 \%$, math-science women $=82 \%$, and nonmath-nonscience women $=$ $73 \%$. For men, more math-science participants indicated a mathscience course as their favorite, compared with nonmathnonscience participants, for an effect size difference between proportions (Cohen, 1988) of $h(632,126)=.46, p<.01$. For women, more math-science participants indicated that their favorite course was within the math-sciences, compared with nonmathnonscience participants, for an effect size difference of $h(258$, $90)=.22, p<.05$. Men and women, within degree group, did not differ in their course preferences, math-science: $h(632,258)=$ $.11, n s$; nonmath-nonscience: $h(126,90)=-.13, n s$.

Discriminant function analysis. An incremental stepwise discriminant function analysis was performed, which included all of the variables presented previously, namely, SAT-M and SAT-V, the number of advanced math-science courses taken in high school, favorite course in high school, the five SOV scales, and sex. High school math-science coursework was the single best 
discriminator between the degree groups, explaining $6.6 \%$ of the variance alone, $F(1,1108)=77.8, p<.01$. Favorite course was the next variable to be added to the prediction model, adding another $1.8 \%$ of variance explained, $F(1,1107)=20.8, p<.01$. The social scale of the SOV was the next best discriminator, adding another $1.6 \% F(1,1106)=18.3, p<.01$, followed by the SAT-M and the SAT-V, adding increments of $0.9 \%$, and $0.3 \%$ of explained variance, $F(1,1105)=10.5, p<.01, F(1,1104)=3.2$, $p<.08$, respectively, resulting in an explanation of $10.9 \%$ of the variance between the math-science and nonmath-nonscience groups. Sex and the remaining four SOV scales did not add any statistically significant explanatory power. In fact, by itself, sex yielded a squared multiple correlation of only .01, independent of all other variables.

\section{Phase II}

Given the previously described data regarding the determination of group membership, Phase II attempts to understand the psychological nature of these groups by examining their subsequent educational and vocational development and more general lifestyle.

Undergraduate experiences. Math-science and nonmathnonscience groups were quite similar to one another with respect to the reasons they cited for their choices of undergraduate majors. Factors included participants' interest in the area and enjoyment of the subject (36\%), followed by their perceptions of future career opportunities and earning potential in the field (12\%). Several participants indicated that the need for a challenge that fully utilized their abilities (12\%) influenced their choice of major. No significant differences among the groups emerged on any of the variables examined.

When asked to indicate all reasons for their change of major, $78 \%$ of nonmath-nonscience respondents cited a change of interest, $39 \%$ said the coursework or field was not what they expected, $26 \%$ indicated that the program was too difficult, $16 \%$ said there were too many math or science requirements, and $13 \%$ cited limited career opportunities or earning potential. Because of the small number of respondents to this query $(N=86)$, results are reported combined across sex.

Graduate educational experiences. Table 3 reports on the graduate degrees earned by study participants. Approximately a third of participants in either degree group earned master's degrees, and a fifth earned doctoral-level degrees. Although slightly more master's degrees were earned by math-science men than nonmath-nonscience men, there were no significant differences in proportions of earned master's degrees between math-science women and nonmath-nonscience women. There were no observed sex differences, within either degree group, for master's degrees. Men earned doctoral-level credentials at comparable rates across degree groups; however, for women, slightly more math-science participants than nonmath-nonscience participants earned doctoral-level degrees. Further, no significant sex differences, within degree groups, were demonstrated for doctoral-level degrees. The small differences observed between math-science and nonmathnonscience groups in earned educational credentials could be anticipated from the degree group differences in mathematical and verbal reasoning abilities, given that highest education level is significantly correlated with SAT-M and SAT-V, multiple correlation $=.21, p<.01$.

Occupations. An analysis of the occupations reported by participants at the Age 33 follow-up revealed that the majority of math-science participants were employed in math-science-related occupations, and the majority of nonmath-nonscience participants were employed in nonmath-nonscience domains (see Table 4). However, some shift across domains was evident: $26 \%$ of participants who earned a math-science undergraduate degree were employed in nonmath-nonscience occupations, and $17 \%$ of nonmath-nonscience participants (i.e., individuals who declared a math-science undergraduate major at Age 18 but received a nonmath-nonscience undergraduate degree) returned to a math-

Table 3

Graduate Degrees Earned, Percentages by Undergraduate Degree Group and Sex

\begin{tabular}{|c|c|c|c|c|c|c|c|c|}
\hline \multirow[b]{3}{*}{ Degree } & \multicolumn{4}{|c|}{ Group proportion } & \multicolumn{4}{|c|}{ Effect size difference } \\
\hline & \multicolumn{2}{|c|}{ Men } & \multicolumn{2}{|c|}{ Women } & \multicolumn{2}{|c|}{$\begin{array}{c}\text { Degree group } \\
\text { difference (within sex) }\end{array}$} & \multicolumn{2}{|c|}{$\begin{array}{c}\text { Sex difference } \\
\text { (within degree group) }\end{array}$} \\
\hline & $\mathrm{MS}^{\mathrm{c}}$ & Non $^{\mathrm{d}}$ & $\mathrm{MS}^{\mathrm{e}}$ & $\operatorname{Non}^{\mathrm{f}}$ & Men & Women & MS & Non \\
\hline MA & 39 & 26 & 35 & 30 & $0.28^{* *}$ & 0.11 & 0.08 & -0.09 \\
\hline JD & 2 & 8 & 1 & 7 & $-0.29 * *$ & $-0.34 * *$ & 0.08 & 0.04 \\
\hline $\mathrm{PhD}$ & 14 & 5 & 8 & 1 & $0.31 * *$ & $0.37 * *$ & $0.19 *$ & 0.25 \\
\hline MD & 8 & 8 & 14 & 4 & 0.01 & $0.36 * *$ & $-0.19^{*}$ & 0.16 \\
\hline All doctorates & 23 & 20 & 22 & 12 & 0.07 & $0.27 *$ & 0.02 & 0.22 \\
\hline
\end{tabular}

Note. The unit of analysis is the participant, not the degree. Therefore, although some participants earned multiple degrees at a given level (e.g., two master's degrees), not all of the degrees earned are necessarily reflected in this table. However, two separately categorized graduate degrees (e.g., a master's and a $\mathrm{PhD}$ ) do both appear. $\mathrm{MS}=$ math-science; $\mathrm{Non}=$ nonmath-nonscience; $\mathrm{MA}=$ master's; JD = doctor of jurisprudence; $\mathrm{PhD}=$ doctor of philosophy; $\mathrm{MD}=$ doctor of medicine

${ }^{a}$ Positive effect sizes reflect greater math-science group proportion; negative effect sizes reflect greater nonmath-nonscience proportion. $\quad{ }^{\mathrm{b}}$ Positive effect sizes reflect greater male proportion; negative effect sizes reflect greater female proportion. ${ }^{\mathrm{c}} n=633 .{ }^{\mathrm{d}} n=127 .{ }^{\mathrm{e}} n=259 .{ }^{\mathrm{f}} n=91$. $* p<.05, * * p<.01$ (following Cohen, 1988, Table 6.3, pp. 192-195). 
Table 4

Occupations, Percentages by Degree Groups and Sex

\begin{tabular}{|c|c|c|c|c|}
\hline \multirow[b]{2}{*}{ Occupation } & \multicolumn{2}{|c|}{ Men } & \multicolumn{2}{|c|}{ Women } \\
\hline & $\mathrm{MS}^{\mathrm{a}}$ & Non $^{\mathrm{b}}$ & $\mathrm{MS}^{\mathrm{c}}$ & Non $^{\mathrm{d}}$ \\
\hline \multicolumn{5}{|c|}{ Math-science } \\
\hline Engineering & 30.4 & 0.0 & 16.0 & 0.0 \\
\hline Math, computer science & 19.1 & 6.9 & 9.8 & 3.9 \\
\hline Medical doctors ${ }^{\mathrm{e}}$ & 9.9 & 6.9 & 17.3 & 3.9 \\
\hline Professors of math-science & 6.2 & 2.9 & 4.9 & 1.3 \\
\hline Natural science & 6.2 & 2.0 & 4.4 & 1.3 \\
\hline Health assessment-treatment $\mathrm{f}^{\mathrm{f}}$ & 0.4 & 0.0 & 9.3 & 3.9 \\
\hline Total & 72.2 & 18.6 & 61.8 & 14.3 \\
\hline
\end{tabular}

Nonmath-nonscience

\begin{tabular}{lrrrr} 
Executive, management related & 15.6 & 48.0 & 14.7 & 42.9 \\
Lawyers, judges & 1.5 & 5.9 & 1.3 & 9.1 \\
Technical support & 1.5 & 2.0 & 2.2 & 1.3 \\
Teachers, librarians & 1.1 & 0.0 & 2.2 & 5.2 \\
Sales & 0.8 & 3.9 & 0.9 & 5.2 \\
Entertainers, public relations & 0.8 & 5.9 & 0.9 & 1.3 \\
Career military officer & 1.1 & 2.9 & 1.3 & 0.0 \\
Professors of nonmath-nonscience & 0.9 & 2.0 & 1.8 & 1.3 \\
Social or religious service & 0.4 & 2.9 & 0.4 & 3.9 \\
Social science, urban planning & 0.4 & 0.0 & 0.9 & 2.6 \\
Administrative support & 0.2 & 1.0 & 1.3 & 0.0 \\
Construction, farm, motor & 0.8 & 1.0 & 0.0 & 0.0 \\
Federal government & 0.2 & 1.0 & 0.0 & 3.9 \\
& & & & \\
Total & 25.2 & 76.5 & 28.0 & 76.6 \\
\hline
\end{tabular}

Other

\begin{tabular}{lllll} 
Homemakers & 0.0 & 0.0 & 7.6 & 3.9 \\
Students & 1.7 & 1.0 & 2.2 & 3.9 \\
Self-employed & 0.6 & 2.9 & 0.4 & 1.3 \\
Unemployed & 0.4 & 1.0 & 0.0 & 0.0 \\
\hline
\end{tabular}

Note. All values in table represent percentages. MS = math-science; Non $=$ nonmath-nonscience

${ }^{\mathrm{a}} n=533 . \quad{ }^{\mathrm{b}} n=102 . \quad{ }^{\mathrm{c}} n=225 . \quad{ }^{\mathrm{d}} n=77 . \quad{ }^{\mathrm{e}}$ Includes physicians, veterinarians, dentists, and opticians. ${ }^{\mathrm{f}}$ Includes registered nurses, pharmacists, and physical and occupational therapists.

science domain to work. This finding questions, at least for intellectually talented groups, the widely held assumption that once one leaves the math-science pipeline, it is very hard to return.

Math-science participants were most commonly found in engineering, mathematics or computer science, and medical doctor professions. Of those math-science participants who were employed in nonmath-nonscience positions, the majority were found in executive or managerial positions.

Nonmath-nonscience participants were most commonly employed in executive or managerial positions. Several were lawyers or judges. Approximately one third of nonmath-nonscience undergraduate majors in math-science occupations were in mathematics or computer science, and another third were medical doctors.

Using Stevens and Hoisington's (1987) scale of occupational prestige, the occupations chosen by study participants were highly prestigious, relative to general population norms of 39.5 $(S D=14.1)$ for men and $39.5(S D=13.1)$ for women. The mean (and standard deviation) prestige scores were 62.9 (11.2) for math-science men, 58.7 (12.3) for nonmath-nonscience men, 63.0 (11.8) for math-science women, and 58.1 (11.4) for nonmathnonscience women. Effect size differences, within degree groups, were as follows: $d(623,126)=.37, p<.01$, for men, and $d(258$, $90)=.42, p<.01$, for women. Although degree group differences were demonstrated, no significant sex differences for occupational prestige, within degree group, were observed, math-science: $d(623,258)=-.02, n s$, nonmath-nonscience: $d(126,90)=.04$, $n s$.

Lifestyle dimensions and preferences. Table 5 reports participants' perceptions of various life dimensions at the time of the Age 33 follow-up. Among both men and women, math-science and nonmath-nonscience groups did not vary in their satisfaction with their careers or on their ratings of their career success. Groups, within sex, did not differ on the more objective measures of total family income or primary income. Math-science and nonmath-nonscience groups also were similar in the number of hours devoted to work, family, leisure, and socializing. No differences between degree groups were apparent for religious service attendance or the number of leadership positions held (all $p \mathrm{~s}>$ $.05)$.

Several sex differences, within degree group, did emerge (see Table 5). Men reported higher primary incomes than women within both math-science and nonmath-nonscience groups. Furthermore, within both degree groups, men reported more hours worked per week than women, and conversely, women reported more hours spent with family than men. A variety of personal preference and importance items (e.g., full-time vs. part-time career options; personal, family, and community commitments) revealed no significant group differences (see Webb, 2001) beyond the sex differences observed in an earlier comprehensive study of all SMPY participants (see Benbow et al., 2000, p. 477, Figure 2).

\section{Discussion}

This study followed 1,110 highly able (top $1 \%$ in mathematical reasoning) individuals who had declared after high school an intention of earning a math-science undergraduate degree. More boys than girls are identified as mathematically talented in talent searches that use the top 1\% criterion (Benbow, 1988); a male: female ratio of 1.8:1.0 was observed in the initial SMPY sample. This ratio diverged to 2.2:1.0 with this study's selection criterion of participants with math-science aspirations, and to 2.4:1.0 for earned undergraduate degrees in the math-sciences. The personal attributes examined here shed light on this phenomenon.

One educationally relevant reason for sex differences in outcomes may be that mathematically precocious women tended to be more verbally talented than mathematically precocious men and, thus, more readily gravitated toward opportunities that draw on verbal-linguistic skills. In support of this idea, a recent independent study of 320 profoundly able (top 1 in 10,000) students compared groups with contrasting intellectual profiles. Regardless of sex, those with high-math tilted profiles (math scores at least 1 $S D$ above their verbal scores) were much more likely to pursue math-science degrees than those with high-flat profiles (more uniform math and verbal scores), despite practically no observed difference in the average SAT-M scores of the two groups (Lubinski, Webb, Morelock, \& Benbow, 2001). Indeed, consistent 
Table 5

Life Dimensions

\begin{tabular}{|c|c|c|c|c|c|c|c|c|}
\hline \multirow[b]{3}{*}{ Life dimension } & \multicolumn{4}{|c|}{ Group $(M)$} & \multicolumn{4}{|c|}{ Effect size difference } \\
\hline & \multicolumn{2}{|c|}{ Men } & \multicolumn{2}{|c|}{ Women } & \multicolumn{2}{|c|}{$\begin{array}{l}\text { Degree group } \\
\text { difference } \\
\text { (within sex) }^{\mathrm{a}}\end{array}$} & \multicolumn{2}{|c|}{$\begin{array}{c}\text { Sex difference } \\
\text { (within degree } \\
\text { group) }\end{array}$} \\
\hline & $\mathrm{MS}^{\mathrm{c}}$ & Non $^{\mathrm{d}}$ & $\mathrm{MS}^{\mathrm{e}}$ & $\operatorname{Non}^{f}$ & Men & Women & MS & Non \\
\hline Career satisfaction ${ }^{\mathrm{g}}$ & 5.7 & 5.5 & 5.7 & 5.4 & 0.10 & 0.19 & 0.00 & 0.10 \\
\hline Career success rating ${ }^{g}$ & 5.8 & 5.7 & 5.8 & 5.6 & 0.09 & 0.17 & -0.03 & 0.05 \\
\hline $\begin{array}{l}\text { Total family income, } \\
\text { in } 1,000 \mathrm{~s}\end{array}$ & 99 & 111 & 102 & 95 & -0.17 & 0.13 & -0.05 & 0.24 \\
\hline Primary income, in $1,000 \mathrm{~s}$ & 77 & 76 & 55 & 49 & 0.02 & 0.16 & $0.45 * *$ & $0.55^{* *}$ \\
\hline Work hours per week & 48.7 & 49.0 & 40.8 & 44.2 & -0.02 & -0.22 & $0.62 * *$ & $0.42 * *$ \\
\hline Family hours per week & 17.5 & 18.5 & 28.5 & 24.8 & -0.07 & 0.14 & $-0.57 * *$ & $-0.35^{*}$ \\
\hline Leisure hours per week & 13.8 & 14.1 & 12.3 & 13.3 & -0.04 & -0.11 & 0.17 & 0.10 \\
\hline Social hours per week & 4.7 & 5.2 & 4.6 & 5.0 & -0.14 & -0.08 & 0.01 & 0.05 \\
\hline Religious services in past year & 24.0 & 28.4 & 25.8 & 17.2 & -0.08 & 0.25 & -0.03 & 0.21 \\
\hline $\begin{array}{l}\text { Leadership positions since } \\
\text { high school }\end{array}$ & 1.1 & 1.3 & 0.9 & 1.0 & -0.08 & -0.08 & 0.08 & 0.17 \\
\hline
\end{tabular}

Note. All values in table represent means for group. MS = math-science; Non = nonmath-nonscience.

${ }^{a}$ Positive effect sizes reflect greater math-science group mean; negative effect sizes reflect greater nonmathnonscience mean. ${ }^{\mathrm{b}}$ Positive effect sizes reflect greater male mean; negative effect sizes reflect greater female mean. $\quad{ }^{\mathrm{c}}$ Minimum $n=346 . \quad{ }^{\mathrm{d}}$ Minimum $n=64 . \quad{ }^{\mathrm{e}}$ Minimum $n=147 . \quad{ }^{\mathrm{f}}$ Minimum $n=51 . \quad{ }^{\mathrm{g}}$ These items used a 7-point scale, ranging from 1 (very dissatisfied or very unsuccessful) to 7 (very satisfied or very successful).

$* p<.05 . * * p<.01$.

with those findings, men in our study were observed to have more high-math tilted profiles (their average math scores were 115 points higher than their average verbal scores) and remained in math-science disciplines more frequently than women in our study, who had more flat ability profiles (their average math scores were only 61 points higher than their average verbal scores) and opted to pursue undergraduate degrees outside math-science more often. It appears that both men and women tended to choose majors that mirrored their overall ability patterns.

Personal preferences also appear to play a role in these malefemale disparities. Math-science domains tend to attract individuals inclined toward working with things more than people (Prediger, 1982). Women and men differ on the people-versus-things dimension of individual differences (Lippa, 1998; Lubinski, 2000, p. 421), with women gravitating toward the former and men toward the latter (Achter et al., 1996; Lubinski \& Humphreys, 1990; Schmidt et al., 1998). The choices of majors by women and men in this study are consistent with the findings based on this dimension. This organic-inorganic distinction (Lubinski, Benbow, \& Morelock, 2000) has been observed in other studies, where women were more likely to earn degrees in the humanities and life sciences, and men were more likely to earn degrees in math and inorganic sciences (Benbow et al., 2000; Humphreys et al., 1993; Lubinski, Webb, et al., 2001). It should be noted that, regardless of sex, nonmath-nonscience participants, relative to their mathscience counterparts, demonstrated higher social interests, which underscores further the importance of this personal preference dimension.

Previous research has shown that Age 13 preference assessments of intellectually precocious youth provide an increment to abilities in the prediction of college major (Achter et al., 1999), a pattern similar to the one found in our discriminant function analysis. It is quite noteworthy that we were able to account for over $10 \%$ of the variance of group membership, given that all of the variables utilized in that predictive function (SAT-M, SAT-V, SOV-Social, high school coursework, and course preference) were directly or indirectly involved in the selection of study participants in the first place, serving to severely restrict their range. After all, SMPY participants were selected for their high mathematical reasoning ability (top 1\%) after self-selecting to participate in what many may see as a math competition. Further, participants for this study were selected on the basis of a declared math-science major at Age 18, which was reported to be highly interest driven by participants.

However, it was not the global (high bandwidth) interest measures utilized in other studies that accounted for the most predictive validity in our study, as might have been anticipated by the restricted range of these variables; it was the more molecular (high fidelity) measures (viz., advanced math-science coursework and course preferences) that discriminated between degree groups. Although these molecular variables reflect different math-science backgrounds, ability and interest profiles are in place at an early age (Achter et al., 1996, 1999) and partly drive course selection (Schmidt et al., 1998; Shea et al., 2001). Given that ability and interest profiles are fairly well established before opportunities for differential course selection typically begin, groups distinguishable on key abilities and interests are likely to manifest differential course selection, college majors, and vocational pursuits. In general, any two groups that differ markedly on key abilities and interests that are assigned to uniform educational experiences are unlikely to exhibit equal outcomes across disciplines (Benbow \& Stanley, 1996). 
The present study also found that participants from all degree groups reported similar factors contributing to their selection of majors, with most participants indicating the importance of interests as the primary factor determining their choices. Individuals who had left math-science also cited a change of interest as the primary factor in their decision to pursue another major. Although many participants selected a change in interest as a reason for their change of major (from a provided list of possible reasons), an idiographic examination of their free responses to open-ended questions may imply more a journey of personal self-discovery (e.g., "realization of priorities," "wanted to explore other areas," "became willing to pursue...my interests") than a material change of interest. This finding supports the proposal that malefemale disparities in outcomes may be, in part, a product of male-female disparities in interests.

Sex did not contribute to the explanation of group membership beyond the explanation provided by ability and interest attributes. In fact, for our special population, sex, in isolation, only explained $1 \%$ of the variance of group membership. Men and women who completed degrees in math-science were similar with regard to the individual difference dimensions examined here. Conversely, men and women who left math-science for other educational pursuits shared similar attributes. To be sure, these individual difference dimensions covary with sex (to varying degrees), which makes sex an easily assessed and convenient proxy variable in many studies, capitalizing on group mean differences on related (unobserved) variables. However, it appears that ability and preference patterns, not simply sex, guide choices.

Regardless of degree type or sex, all groups attained extraordinarily high levels of achievement. Overall, participants earned doctorates at more than 20 times base rate expectations of $1 \%$ (U.S. Department of Education, National Center for Education Statistics, 1997). This study also demonstrated that nonmathnonscience participants earned comparable levels of graduate degrees with math-science participants (the small differences in educational credentials were in line with the modest ability differences), although the areas in which they secured those degrees differed. This finding of comparable educational credentials mirrors other research indicating that intellectually talented men and women are securing uniform proportions of advanced educational credentials but differ in the areas in which they pursue those credentials (Benbow et al., 2000; Lubinski, Webb, et al., 2001). This finding is important because it illustrates an often neglected aspect of the male-female parity issue, namely, that similar to the greater representation of men in many inorganic disciplines, women are more greatly represented in many organic disciplines. Insisting on equal representation of men and women across all domains and investing resources to "correct" for these disparities could deny some men and women opportunities to develop according to their unique preferences.

Degree groups did not differ significantly in primary or family income or in how they spent their time each week, allotting a similar number of hours to work, family, socializing, and leisure. However, significant sex differences did emerge on primary income, the number of hours spent at work, and the number of hours spent with family, consistent with findings from other studies indicating sex differences in focus on career versus family (Browne, 1998). The relationships among these three variables must be considered to fully understand these findings: For both degree groups, men worked significantly more hours and spent almost reciprocally fewer hours with family than women. In turn, the observed sex differences in work hours are comparable to the observed sex differences in primary income. In fact, other research has reported that differences in the number of work hours accounted for almost one third of the differences in earnings observed between male and female lawyers (Wood, Corcoran, \& Courant, 1993) and that sex differences in earned income were statistically insignificant when occupational category and the number of hours worked were controlled (Benbow et al., 2000).

Finally, and critically, this study reveals that those students leaving the math-science pipeline for other educational and vocational pursuits appear just as satisfied with their career choices as those who remain in math-science. Regardless of degree group or sex, participants rate their career satisfaction and their success in their careers uniformly high. Moreover, degree groups perceive themselves as equally successful in their chosen professions-and are, as measured objectively by income.

\section{Limitations}

In light of Shea et al.'s (2001) recent finding of the incremental validity of spatial ability in conjunction with mathematical and verbal abilities in the prediction of educational and vocational outcomes in intellectually talented populations (see also Gohm, Humphreys, \& Yao, 1998; Humphreys et al., 1993), incomplete spatial ability data is a definite limitation of this study. With the addition of spatial ability measures, further research on this highly select population is likely to achieve more differentiation than that reported here. Further limiting this study is the lack of personality and temperament measures (e.g., competitiveness, status seeking, and risk taking). The well-documented sex differences on these measures potentially hold import for math-science outcomes (Browne, 1995; Geary, 1998).

\section{Conclusions and Implications}

Mathematically facile men and women who chose to leave math-science for other fields reported career success and satisfaction commensurate with those men and women who remained in math-science fields. These individuals are not underachieving, although perhaps their achievements are underappreciated. Contemporary discourse regarding the math-science pipeline implies that a great societal loss is encountered when a person with high math-science potential (or mathematical reasoning ability) chooses to apply those talents outside engineering or the physical sciences, but why? Is an individual's contribution to environmental law, for example, less valuable than a contribution to chemistry? Both require the utilization of complex scientific theories and data; indeed, quantitative reasoning skills are becoming more generally applicable in our technologically demanding society. Moreover, educational-vocational domains are not truly categorical, even though they are often perceived as such. For example, many participants in this study with nonmath-nonscience degrees were working in math-science occupations. Perhaps discourse needs to be redefined to reflect the generalizability of mathematical talent and the multifaceted nature of the modern work environment.

Providing opportunities for positive development and removing barriers to math-science domains for all groups is certainly ap- 
propriate, but parity of opportunity may not necessarily result in parity of male-female representation across all facets of the educational-vocational spectrum. We cannot afford to ignore the impact that individual differences have on influencing the immediate decision-making processes of individuals or on structuring their subsequent long-term development. As Tyler (1974) emphasized, "a complex society cannot regard its members as identical interchangeable parts of a social machine" (p. 5). Although individual difference assessments are critical for the study of educational-vocational choice and performance after choice, how we choose to apply that knowledge is not a scientific question; it is a question of values. Regardless of how we choose to arrange our opportunity and reward structures (Dawis, 2001; Wells, 1937), asymmetries will occur across our personal values (for expressing individual differences), our political values (for freedom of choice), and our societal values (for order over chaos). Although equal male-female representation across all educationalvocational domains may conflict with allowing people to freely choose their own educational and vocational paths, providing for equal opportunity does not. Perhaps the aspired parity should not be equal representation, but equal opportunity.

\section{References}

Achter, J. A., Lubinski, D., \& Benbow, C. P. (1996). Multipotentiality among the intellectually gifted: "It was never there and already it's vanishing." Journal of Counseling Psychology, 43, 65-76.

Achter, J. A., Lubinski, D., Benbow, C. P., \& Eftekhari-Sanjani, H. (1999). Assessing vocational preferences among intellectually gifted adolescents adds incremental validity to abilities: A discriminant analysis of educational outcomes over a 10-year interval. Journal of Educational Psychology, 91, 777-786.

Allport, G. W., Vernon, P. E., \& Lindzey, G. (1970). Manual: Study of values. Boston: Houghton Mifflin.

Benbow, C. P. (1988). Sex differences in mathematical reasoning ability in intellectually talented preadolescents: Their nature, effects, and possible causes. Behavioral and Brain Sciences, 11, 169-183.

Benbow, C. P., Lubinski, D., Shea, D. L., \& Eftekhari-Sanjani, H. (2000). Sex differences in mathematical reasoning ability: Their status 20 years later. Psychological Science, 11, 474-480.

Benbow, C. P., \& Stanley, J. C. (1996). Inequity in equity: How "equity" can lead to inequity for high potential students. Psychology, Public Policy, and Law, 2, 249-292.

Browne, K. R. (1995). Sex and temperament in modern society: A Darwinian view of the glass ceiling and the gender gap. Arizona Law Review, 37, 971-1106.

Browne, K. R. (1998). An evolutionary account of women's workplace status. Managerial and Decision Economics, 19, 427-440.

Cohen, J. (1988). Statistical power analysis for the behavioral sciences. Hillsdale, NJ: Erlbaum.

Commission on the Advancement of Women and Minorities in Science, Engineering and Technology Development. (2000). Land of plenty. Diversity as America's competitive edge in science, engineering and technology. Retrieved June 26, 2001, from http://www.nsf.gov/od/ cawmset/report.html

Committee on Women Faculty. (1999). A study on the status of women faculty in science at MIT. Retrieved August 26, 1999, from http:// web.mit.edu/fnl/women/women.htm

Dawis, R. V. (1992). The individual differences tradition in counseling psychology. Journal of Counseling Psychology, 39, 7-19.

Dawis, R. V. (2001). Toward a psychology of values. The Counseling Psychologist, 29, 458-465.
Dawis, R. V., \& Lofquist, L. H. (1984). A psychological theory of work adjustment. Minneapolis: University of Minnesota Press.

Geary, D. C. (1996). Sexual selection and sex differences in mathematical abilities. Behavioral and Brain Sciences, 19, 229-284.

Geary, D. C. (1998). Male, female: The evolution of human sex differences. Washington, DC: American Psychological Association.

Gohm, C. L., Humphreys, L. G., \& Yao, G. (1998). Underachievement among spatially gifted students. American Educational Research Journal, 35, 515-531.

Halpern, D. F. (1997). Sex differences in intelligence: Implications for education. American Psychologist, 52, 1091-1102.

Halpern, D. F. (2000). Sex differences in cognitive abilities (3rd ed.). Mahwah, NJ: Erlbaum.

Hedges, L. V., \& Nowell, A. (1995). Sex differences in mental test scores, variability, and numbers of high scoring individuals. Science, 269, $41-45$.

Holden, C. (2000). Parity as a goal sparks bitter battle. Science, 289, 380

How to boost the careers of women in science? (1999). Nature, 401, 99.

Humphreys, L. G., Lubinski, D., \& Yao, G. (1993). Utility of predicting group membership and the role of spatial visualization in becoming an engineer, physical scientist, or artist. Journal of Applied Psychology, 78, $250-261$.

Jensen, A. R. (1998). The g factor: The science of mental ability. Westport, CT: Praeger.

Kimura, D. (1999). Sex and cognition. Cambridge, MA: MIT Press.

Kleinfeld, J. (1998-1999, Winter). The Morella Bill, my daughter Rachel, and the advancement of women in science. Academic Quarterly, 12, $79-86$.

Lane, N. J. (1999). Why are there so few women in science? Nature debates. Retrieved December 27, 1999, from http://helix.nature.com/ debates/women/women_contents.html

Lawler, A. (1999). Tenured women battle to make it less lonely at the top. Science, 286, 1272-1277.

Lawler, A. (2002). Engineers marginalized, MIT report concludes. Science, 295,2192

Lippa, R. (1998). Gender-related individual differences and the structure of vocational interests: The importance of the people-things dimension. Journal of Personality and Social Psychology, 74, 996-1009.

Lubinski, D. (2000). Scientific and social significance of assessing individual differences: "Sinking shafts at a few critical points." Annual Review of Psychology, 51, 405-444.

Lubinski, D., \& Benbow, C. P. (1994). The Study of Mathematically Precocious Youth. In R. F. Subotnik \& K. D. Arnold (Eds.), Beyond Terman (pp. 255-281). Norwood, NJ: Ablex.

Lubinski, D., \& Benbow, C. P. (2000). States of excellence. American Psychologist, 55, 137-150.

Lubinski, D., Benbow, C. P., \& Morelock, M. J. (2000). Gender differences in engineering and the physical sciences among the gifted: An inorganic-organic distinction. In K. A. Heller, F. J. Mönks, R. J. Sternberg, \& R. F. Subotnik (Eds.), International handbook for research on giftedness and talent (2nd ed., pp. 627-641). Oxford, England: Pergamon Press.

Lubinski, D., Benbow, C. P., \& Ryan, J. (1995). Stability of vocational interests among the intellectually gifted from adolescence to adulthood: A 15-year longitudinal follow-up. Journal of Applied Psychology, 80, $196-200$

Lubinski, D., Benbow, C. P., Shea, D. L., Eftekhari-Sanjani, H., \& Halvorson, M. B. (2001). Men and women at promise for scientific excellence: Similarity not dissimilarity. Psychological Science, 12, 309-317.

Lubinski, D., \& Humphreys, L. G. (1990). A broadly based analysis of mathematical giftedness. Intelligence, 14, 327-355.

Lubinski, D., Schmidt, D. B., \& Benbow, C. P. (1996). A 20-year stability analysis of the Study of Values for intellectually gifted individuals from adolescence to adulthood. Journal of Applied Psychology, 81, 443-451. 
Lubinski, D., Webb, R. M., Morelock, M. J., \& Benbow, C. P. (2001). Top 1 in 10,000: A 10-year follow-up of the profoundly gifted. Journal of Applied Psychology, 86, 718-729.

Mervis, J. (1999a). Efforts to boost diversity face persistent problems. Science, 284, 1757-1759.

Mervis, J. (1999b). High level groups study barriers women face. Science, 284, 727.

Mervis, J. (2000). NSF searches for right way to help women. Science, 284, $379-381$.

National Council for Research on Women. (2001). Balancing the equation: Where are the women and girls in science, engineering, and technology? New York: Author.

National Research Council. (2001). From scarcity to visibility: Gender differences in the careers of doctoral scientists and engineers. Washington, DC: National Academy Press.

National Science Foundation. (1996). Program for women and girls in science, engineering, and mathematics. Retrieved September 12, 2002, from http://www.nsf.gov/pubsys/ods/getpup.cfm?nsf96131

Prediger, D. J. (1982). Dimensions underlying Holland's hexagon: Missing link between interests and occupations? Journal of Vocational Behavior, 21, 259-287.

Rivera-Batiz, F. L. (1992). Quantitative literacy and the likelihood of employment among young adults in the United States. Journal of Human Resources, 27, 313-328.

Sax, L. J. (2001). Undergraduate science majors: Gender differences in who goes to graduate school. The Review of Higher Education, 24, 153-172.

Schmidt, D. B., Lubinski, D., \& Benbow, C. P. (1998). Validity of assessing educational-vocational preference dimensions among intel- lectually talented 13-year olds. Journal of Counseling Psychology, 45, $436-453$

Seymour, E., \& Hewitt, N. M. (1997). Talking about leaving: Why undergraduates leave the sciences. Boulder, CO: Westview Press.

Shea, D. L., Lubinski, D., \& Benbow, C. P. (2001). Importance of assessing spatial ability in intellectually talented young adolescents: A 20-year longitudinal study. Journal of Educational Psychology, 93, 604-614.

Stevens, G., \& Hoisington, E. (1987). Occupational prestige and the 1980 U.S. labor force. Social Science Research, 16, 74-105.

Tyler, L. E. (1974). Individual differences. Englewood Cliffs, NJ: PrenticeHall.

U.S. Department of Education, National Center for Education Statistics. (1997). Digest of education statistics, 1997 (NCES 98-015). Washington, DC: Author.

Webb, R. M. (2001). Stability of educational and vocational plans in math/science among young adults identified as mathematically gifted at age 13: A 20-year longitudinal study. Unpublished master's thesis, Vanderbilt University, Nashville, Tennessee

Wells, F. L. (1937). Intelligence and socialization. American Journal of Psychiatry, 93, 1265-1291.

Wickware, P. (1997). Along the leaky pipeline. Nature, 390, 202-203.

Wood, R. G., Corcoran, M. E., \& Courant, P. N. (1993). Pay differences among the highly paid: The male-female earnings gap. Journal of Labor Economics, 11, 417-441.

Received September 21, 2001

Revision received January 4, 2002

Accepted January 7, 2002 